FEATURE

\title{
Brief Intervention to Change Students' Attitudes Regarding Library Research
}

$\mathbf{M}$ any students who would benefit from a reference librarian's help do not ask for assistance. This study experimentally tests whether having students read a brief passage can shift attitudes. Two hypotheses are experimentally tested: (1) students who read about students' positive interactions with librarians will express significantly greater comfort to seek help from librarians; (2) students who read positive accounts of students' efforts to become good researchers will express significantly greater willingness to work at becoming proficient researchers. The two hypotheses were not supported. However, students who read about positive interactions with librarians expressed significantly less confidence in their ability to conduct library research. This unexpected finding suggests that a brief intervention may be an effective way to begin a library instruction session.

The reasons why students may not avail themselves of help from reference librarians are various and complex. Understanding those reasons can provide useful insights, but the challenge is what to do about underutilization of reference services. The purpose of this study is to experimentally test whether having students read a brief passage can shift attitudes regarding library research and comfort asking for help. We employ a standard, very well-established experimental method whereby all variables are kept as equal as possible, except for the content of a reading designed to have students think about how they feel regarding library research and asking for help. The results surprised us.

\section{LITERATURE REVIEW}

Librarians have long recognized that many people who could benefit from a librarian's help do not ask. Investigations into why that happens and suggestions for ways to overcome the problem can be found in the literatures of library science, college student services, and educational psychology. Concerns regarding how to overcome patrons' unwillingness to seek help have been expressed in the library literature since 1876. Samuel Green's seminal article in the inaugural volume of Library Journal emphasized the need for librarians to put patrons at ease, to have sympathy, patience, and a welcoming demeanor. ${ }^{1}$ Bunge's 1984 review of literature on interpersonal relations between librarians and patrons drew on dozens of studies and

\section{Steve Black and Ross \\ Krawczyk}

Steve Black (seblack@colgate.edu)

is Associate University Librarian

at Colgate University, Hamilton,

New York, and Ross Krawczyk

(krawczyr@strose.edu) is Assistant

Professor of Psychology, The College

of Saint Rose, Albany, New York.

Reference \& User Services Quarterly, vol. 56, no. 4, pp. 277-284

(c) 2017 American Library Association. All rights reserved.

Permission granted to reproduce for nonprofit, educational use. 


\section{FEATURE}

commentaries, many of which emphasized the importance of being sensitive to patrons' psychological needs. ${ }^{2}$ Insights from the fields of communications and counseling influenced the practice of reference librarianship in the 1970s, in particular the importance of librarian's nonverbal communication and question negotiation skills. ${ }^{3}$

How to best communicate what libraries can do to help people remains an important issue today. Brophy has argued for the essential place of narrative and storytelling in librarians' management of and advocacy for library services. ${ }^{4} \mathrm{Li}$ brary patrons may be more responsive to a narrative than to a list of facts, so employing stories can be an effective means of conveying information during interactions such as reference interviews and library instruction sessions. ${ }^{5}$

Communication and narrative are important, but quantitative measurement has long played a key role in the assessment of library effectiveness. A landmark study conducted in 1983 sought to identify what library resources and activities lead to patrons receiving correct answers to their questions. Gers and Seward found that extent of resources had very little to do with librarians' performance, rather that successful transactions were overwhelmingly due to the behaviors of individual librarians. ${ }^{6}$ They also found that correct answers were provided only 55 percent of the time, a finding corroborated by others. ${ }^{7}$ The so-called " 55 percent rule" of correct responses has been challenged as being unfair because a successful transaction encompasses more than giving presupposed correct answers to prepared questions. Durrance asserted that patrons' willingness to return is a better measure of success. ${ }^{8}$ These findings resonated with many reference librarians' perceptions of their own professional experience.

The Reference and User Services Association decided to establish an ad hoc committee to define best practices, first published in 1996 as "Guidelines for Behavioral Performance of Reference and Information Service Professionals." These best practices emphasize the importance of being approachable, interested, an effective communicator, and persistent in ensuring the questioner's needs have been met. Unfortunately, librarians may not always adhere to the guidelines, ${ }^{10}$ which negatively impacts students' willingness to return. Negative experiences may also exacerbate the well-known problem that students often do not understand the role of reference librarians. ${ }^{11}$

Students who have never had a transaction with a librarian may avoid asking for help for other reasons. They may be experiencing feelings of anxiety about using the library. ${ }^{12}$ College libraries are usually much larger than what students have experienced before, so the scale and complexity of systems and physical arrangements may leave them confused..$^{13}$ This happens in the context of students' fresh experiences at a college or university, likely causing some degree of feeling lost or overwhelmed. ${ }^{14}$ Anyone who experiences a dramatically new environment will experience some feelings of uncertainty. In addition, Blundell and Lambert found that not only are some students anxious about doing library research, but many also exhibit inadequate motivation and willingness to learn. ${ }^{15}$ Students, especially freshmen, tend to rely on skills learned in high school and can be reluctant to accept the challenge of learning more complex and nuanced ways to conduct research. ${ }^{16}$ Kwon has shown that although anxiety impacts many students, a positive disposition toward critical thinking helps students overcome the debilitating effects of anxiety. ${ }^{17}$ The literature thus suggests that although students are likely to initially feel uncomfortable doing library research, willingness to apply oneself is key to overcoming that obstacle.

The degree of unease students may feel in a new environment varies by individual. So does the willingness to recognize the need for help and to seek it out. Reluctance to seek academic help may be due to effort abandonment, overconfidence, stereotype threat, need for autonomy, or threat to self-esteem..$^{18}$ Effort abandonment is simply giving up, perhaps even before investing serious effort. Overconfident students might skip asking for help because they are not sufficiently aware of what they need to learn to succeed. Unfortunately, someone who is incompetent at something "not only [will] reach erroneous conclusions and make unfortunate choices, but their incompetence robs them of the ability to realize it." 19

Other causes of help avoidance are not based on lack of knowledge. Members of stereotyped groups may choose to go it alone if they feel that asking for help threatens to reinforce others' judgments or that their own actions will match the stereotype. ${ }^{20} \mathrm{~A}$ desire to be autonomous leads some students to conclude that figuring it out alone is a better way to learn. Also, asking for help is an admission of a lack of knowledge or skill, which can be perceived by many as a threat to self-esteem. Issues of self-esteem are particularly salient for students sensitive to their social status, as they may be more likely to perceive asking for help as a threat to their self-worth. ${ }^{21}$ Fear of revealing personal incompetence may be heightened if students think their struggles are unique. ${ }^{22}$

Given the impact of individuals' emotional responses to situations where seeking academic help is educationally appropriate, it is beneficial to investigate practical methods to stimulate more positive attitudes toward academic helpseeking. Brief, easily administered interventions may shift attitudes. Social-psychological interventions can be effective if they target students' subjective experiences, convey relevant psychological ideas, and tap into ongoing processes in the education environment. ${ }^{23}$ Simple interventions rely on effective persuasion and attitude change to convey ideas and alter mind-sets. ${ }^{24}$ Interventions designed to enhance students' sense of social connectedness have been found to enhance achievement motivation, even through something as simple as discovering that one shares a birthday with a classmate. ${ }^{25}$

Brief interventions have the potential to improve academic outcomes if they are administered in a context of opportunity for learning. ${ }^{26}$ For example, Walton and Cohen found that an experiment designed to mitigate African American students' doubts of social belonging in college 
not only boosted the students' confidence but also raised their grades. ${ }^{27}$ Social psychological interventions have the potential to reduce educational disparities because when employed wisely, even brief interventions can have lasting effects. ${ }^{28}$ Wilson, Damiani, and Shelton argue that the only way to find out the types of intervention that are most effective is to conduct experiments where the intervention group is compared with the control group in an experimentally sound manner. ${ }^{29}$ Lazowski and Hulleman's recent meta-analysis of seventy-four motivational interventions in education found that experimentally manipulating an independent variable is generally effective, and they assert that intervention studies provide insight into causal relationships in ways that observational studies cannot. ${ }^{30}$ The authors argue that "we need more intervention research, design-based and experimental, that develops and tests operationalized theories in education contexts." ${ }^{31}$

Published studies have thus demonstrated the potential benefits of social-psychological interventions to influence students' attitudes about learning. But none to date have specifically addressed the potential for an intervention to increase students' level of comfort to seek academic help from a librarian when confronted with the need to conduct research. The intervention studies cited above required an hour or more of students' time. Librarians rarely if ever have the luxury of spending that much time with students. This experiment explores whether a very short intervention designed to be administered by a librarian during a class visit can influence students' mindsets regarding library research. The researchers test whether a brief, easily administered intervention can shift students' attitudes.

\section{HYPOTHESES}

1. Students who read a narrative about students' positive interactions with librarians will express significantly greater comfort to seek help from librarians compared to a control group of students who read facts about the library.

2. Students who read a narrative about positive efforts to become good researchers will express significantly greater willingness to work at becoming proficient researchers compared to a control group of students who read facts about the library.

\section{METHOD}

The instrument was administered to students in sections of a required expository writing, oral communication, and research course at a liberal arts college in the Northeastern United States. The course is populated mostly by freshmen but some classes include a few transfer students. Each section is capped at 18 students. The college's population is 4,500 students. The freshman class is 57 percent white, 12 percent
Black or African American, 10 percent Hispanic/Latino, 8 percent two or more races, 3 percent Asian, 5 percent nonresident alien, and 6 percent race/ethnicity unknown. The authors sent requests to the instructors of the seventeen sections of the course offered in Spring 2016 to allow us to administer the instrument in their class, and instructors in thirteen sections agreed to participate. The procedure was approved in advance by the college's Institutional Research Board (IRB).

The lead author (Black) visited the classes in person and introduced himself as a librarian. He told students that their responses to statements about library research were voluntary but appreciated since their input provides librarians valuable information. Students were given printed forms with a brief reading on the front and six response items on the back (see appendix). Forms for each class were arranged in random order. The researchers used the list function at Random.org to randomize each set of eighteen forms. The reading administered to the randomly selected control group matched odd numbers, and the reading administered to the randomly selected treatment group matched even numbers. All students were asked to read the passage and then respond to the items on the back. The instrument recorded no demographic or personal information. The instrument was designed to be completed within three minutes.

Students randomly selected for the control group read facts about the library (see appendix). Students randomly selected for the treatment group read a narrative dialogue among college seniors describing their positive experiences using the library and learning to do research (see appendix). The dialogue was invented by the authors based on accounts of students' reactions to library research reported by Mellon, ${ }^{32}$ Kulthau, ${ }^{33}$ and Project Information Literacy. ${ }^{34}$ The readings were designed to have similar readability. The reading for the control group was 352 words and had a readability of Flesch-Kincaid Grade Level 6. The reading for the treatment group was shorter with 305 words but with a higher Flesch-Kincaid Grade Level (7.6). A more closely matched readability level would have been ideal, because the treatment and control groups should have as equal an experience as possible, save for the content of the reading. But the vocabulary necessary to describe library resources and services for the control condition elevated the reading level, and the authors' efforts to raise the reading level for the narrative of positive experiences for the experimental condition caused the dialogue to seem unnatural.

The response items were identical for both forms. The items were run through QUAID (Question Understanding Aid $)^{35}$ and edited in response to QUAID's suggestions regarding the avoidance of unfamiliar technical terms, vague or imprecise relative terms, vague or ambiguous noun-phrases, complex syntax, and working memory overload. QUAID identified "librarian" and "researcher" as terms that may be unfamiliar to some respondents, but those were kept because of their essential use in this context.

When the students finished reading and responding to the items, Black explained that there were two different 


\section{FEATURE}

Table 1. Distribution of Responses for Students Who Read Factual Information about the Library Compared to Those Who Read about Positive Interactions with Librarians While Conducting Research $(n=185)$.

\begin{tabular}{|c|c|c|c|c|c|c|}
\hline & & SA & A & $\mathbf{N}$ & D & SD \\
\hline \multirow[t]{2}{*}{ I feel confident today about my ability to do library research. } & facts & $27 \%$ & $57 \%$ & $8 \%$ & $7 \%$ & $1 \%$ \\
\hline & narrative & $7 \%$ & $34 \%$ & $28 \%$ & $24 \%$ & $6 \%$ \\
\hline \multirow[t]{2}{*}{ I can become better at library research if I work hard. } & facts & $44 \%$ & $44 \%$ & $10 \%$ & $1 \%$ & $1 \%$ \\
\hline & narrative & $35 \%$ & $53 \%$ & $10 \%$ & $1 \%$ & $0 \%$ \\
\hline \multirow[t]{2}{*}{ I feel comfortable asking a librarian for help. } & facts & $38 \%$ & $46 \%$ & $10 \%$ & $6 \%$ & $0 \%$ \\
\hline & narrative & $26 \%$ & $53 \%$ & $14 \%$ & $5 \%$ & $1 \%$ \\
\hline \multirow[t]{2}{*}{ I should learn to use the library by figuring it out by myself. } & facts & $9 \%$ & $21 \%$ & $42 \%$ & $27 \%$ & $1 \%$ \\
\hline & narrative & $6 \%$ & $9 \%$ & $47 \%$ & $30 \%$ & $7 \%$ \\
\hline \multirow[t]{2}{*}{ I would not want my friends to know if I ask a librarian for help. } & facts & $4 \%$ & $0 \%$ & $11 \%$ & $34 \%$ & $51 \%$ \\
\hline & narrative & $0 \%$ & $1 \%$ & $20 \%$ & $34 \%$ & $44 \%$ \\
\hline \multirow[t]{2}{*}{ With practice I will become an excellent researcher. } & facts & $41 \%$ & $52 \%$ & $4 \%$ & $2 \%$ & $1 \%$ \\
\hline & narrative & $37 \%$ & $52 \%$ & $9 \%$ & $1 \%$ & $0 \%$ \\
\hline
\end{tabular}

Note: $\mathrm{SA}=$ Strongly Agree, $\mathrm{A}=$ Agree, $\mathrm{N}=$ neither agree nor disagree, $\mathrm{D}=$ disagree, $\mathrm{SD}=$ strongly disagree

readings. He explained that having two readings was intended to measure whether reading facts versus a narrative influences students' attitudes regarding library research. Students were asked if they had any questions, and were invited to contact the researcher if they wanted additional information about the study.

The instrument took students about three minutes to complete, as intended. Students were very cooperative, and exceptionally few forms had missing data. One minor difficulty arose with students who arrived to class late. Those who arrived one or two minutes late were administered the instrument. This prolonged the total time taken to about five minutes in the classes where one or more students arrived late. Students who arrived more than a few minutes late were told that participation was voluntary and were not administered the instrument. At the conclusion, when given the opportunity to do so, no students asked questions or provided comments.

The outcome variables in the current study were comfort asking a librarian for help and willingness to work hard to improve as a researcher. These variables were measured by summing relevant items. Using multiple items, rather than a single item, to represent a variable provides superior reliability and validity of measurement. The outcome variable of "comfort" used in hypothesis 1 was created by summing item 3, "I feel comfortable asking the librarian for help" reverse-scored so that higher scores indicate more comfort, and item 4, "I should learn to use the library by figuring it out by myself." Higher scores indicate greater comfort. The outcome variable of "willingness to work" used in hypothesis 2 was created by summing item 2, "I can become better at library research if I work hard," and item 6, "With practice I will become an excellent researcher," both reverse-scored so that higher scores indicate more willingness. The outcome variable of "confidence" used in the exploratory analyses was created by reverse-scoring item 1 , "I feel confident today about my ability to do library research," with higher scores indicating greater confidence.

\section{RESULTS}

The students' responses to the items are shown in table 1 . The first hypothesis stated students who read a narrative of students' positive interactions with librarians while conducting research will express significantly greater willingness to seek help from librarians compared to a control group of students who read facts about the library. To test this hypothesis, researchers utilized an independent samples t-test to measure the significance of difference between groups' means (M) and standard deviations (SD). Results revealed no significant differences between the positive interactions group $\mathrm{M}=7.22(\mathrm{SD}=1.17)$ and the factual group $\mathrm{M}=7.06$ $(\mathrm{SD}=1.23), t(185)=.942, p=.348$. The hypothesis was not supported as both groups reported equal comfort.

The second hypothesis stated students who read a narrative of positive interactions with librarians while conducting research will express significantly greater willingness to work at becoming proficient researchers compared to a control group of students who read facts about the library. To test this hypothesis, researchers utilized an independent samples $t$-test. Results revealed no significant differences between the narrative group $\mathrm{M}=8.50(\mathrm{SD}=1.14)$ and the facts group $\mathrm{M}=8.58(\mathrm{SD}=1.34), t(186)=-.495, p=.622$. The hypothesis was not supported as both groups reported equal willingness to work. Descriptive and inferential statistics for the hypotheses and exploratory analysis described in the following paragraph are shown in table 2. (insert table 2)

Given the lack of significant group differences on the two primary outcome variables that tested the hypotheses, 
Table 2. Descriptive and Inferential Statistics for Students Who Read a Narrative of Positive Interactions with Librarians While Conducting Research Compared to Those Who Read Facts about the Library.

\begin{tabular}{|c|c|c|c|c|c|c|}
\hline \multirow[b]{2}{*}{ Variable } & \multicolumn{2}{|c|}{ Narrative } & \multicolumn{2}{|c|}{ Facts } & \multirow[b]{2}{*}{$\mathrm{t}$} & \multirow[b]{2}{*}{$\mathrm{p}$} \\
\hline & M & SD & M & SD & & \\
\hline Comfort Seeking Help & 7.22 & 1.17 & 7.06 & 1.23 & 0.94 & 0.35 \\
\hline Willingness to Work & 8.50 & 1.14 & 8.58 & 1.34 & -.495 & 0.62 \\
\hline Confidence & 3.12 & 1.05 & 4.02 & 0.85 & -6.41 & $<0.001$ \\
\hline
\end{tabular}

Note: $\mathrm{M}=$ Mean; $\mathrm{SD}=$ Standard deviation

researchers conducted an exploratory analysis to examine the intervention's effect on students' confidence in their ability to do library research. An independent samples t-test revealed that students in the narrative condition $\mathrm{M}=3.12$ (SD $=1.05$ ) reported significantly lower confidence than those in the facts condition $\mathrm{M}=4.02(\mathrm{SD}=.85), t(186)=-6.41, p<$ .001 . This finding indicated that students who read the narrative about positive interactions with librarians while conducting research reported significantly reduced confidence when compared to students who read facts about the library.

\section{DISCUSSION}

The answer to the overarching question "Can a brief, easily administered intervention shift students' attitudes?" is "Yes, but not in the ways hypothesized." The treatment group that read a narrative of positive experiences expressed neither more comfort in asking a librarian for help nor greater intent to work hard to become a proficient researcher. To our surprise the overwhelmingly most significant impact on the treatment group was the difference in responses to "I feel confident today about my ability to do library research." The students who read the dialogue describing positive interactions with librarians while conducting research expressed significantly less confidence. The reasons for this invite further investigation, but we surmise the effect is because the treatment reading raised students' awareness of what they will need to learn to become proficient researchers. The narrative may have shifted their unawareness of what they did not know into a more accurate self-assessment of current proficiency.

This surprise result suggests the possibility that this intervention may be an effective way to introduce a library instruction session. If exposure to challenges and strategies used to overcome difficulties heightens awareness among students of what they will need to learn, a brief intervention may prime them to be more receptive to a librarian's instruction.

The researchers were somewhat surprised by how few students agreed with the statement "I would not want my friends to know if I ask a librarian for help." The research on help-seeking behaviors cited in the literature review above posits the protection of self-esteem as a significant reason students may be reluctant to ask for help from librarians or student support service personnel. It is reasonable to believe that concern for status among peers might cause students to not want to expose their need for help. The overwhelming disagreement with not wanting friends to know indicates peer status concerns to be a minor impediment to seeking help from librarians, at least with the population represented here.

\section{LIMITATIONS}

Further investigation is needed to assess the generalizability of these results. This experiment was conducted with primarily freshmen in their second semester at a private college of 4,500 students. The degree to which results would be similar with students from other institutions or with students in different stages of their academic careers is not known. The surprise effect of the intervention reducing current confidence may be diminished or absent if administered to more experienced students.

While the instrument was well received by students and yielded useful data, it could be improved. Although the wording of the narrative dialogue describing students' experience was gleaned from prior research, it's possible that words such as "scared" and "stupid" triggered reactions that other words conveying similar meaning might not. It would be beneficial to test the effects of various wordings. Another improvement would be to add items to allow responses to be tested for internal reliability. For example, along with "I feel comfortable asking a librarian for help," one could add "Asking a librarian for help can benefit me." Researchers could then analyze the degree to which responses were similar for items intended to test the same construct. It would be useful to know whether students react to "comfort" differently from "benefit." With only six items, researchers were limited in our ability to test the interaction of factors that affect student attitudes. But more items mean a longer time to administer the instrument, a tradeoff to always keep in mind.

\section{FURTHER RESEARCH}

This sample was fairly large, $n=185$, but it represented the population of mostly freshmen at one college. The degree to which these results generalize to other college students 


\section{FEATURE}

can only be established by repeating this experiment with additional groups of subjects. The current study gathered no demographic data. Future studies could investigate differences in effects of intervention by factors such as gender, race, ethnicity, or first generation to attend college.

The current experiment employed a brief reading administered on paper. A similar intervention could employ video or audio, either in the classroom or online. Other media and instructional settings could be found to have equal or greater efficacy in shifting students' attitudes. Relative impacts of different wording could also be explored. Changes to wording could be minor, or the text could be entirely reworked to address different attitudes. As Wilson, Damiani, and Shelton noted, the only way to discover the most effective interventions is by experimenting with instruments and settings with various populations. ${ }^{36}$

\section{CONCLUSION}

The intervention had no significant impact on students' level of comfort to seek help from librarians, nor did it significantly impact students' expressed willingness to work at becoming proficient researchers. The primary finding of this study is that an intervention designed to increase students' comfort level to seek help and their willingness to work hard had the unintended consequence of reducing students' current confidence in their ability to conduct library research. Replication is needed to generalize, but if this finding broadly reflects college freshmen it has important implications for information literacy instruction. Kroll describes the intellectual growth of freshmen as including a process of moving from ignorant certainty to intelligent confusion. ${ }^{37}$ Apparently, the reading about interactions with librarians generated intelligent confusion. An intervention like ours can make students more aware of their personal needs to learn and thus lead them to be more attentively engaged in library instruction. The implication for how librarians present information literacy is that instruction should include an intervention designed to alert students to what they do not know and intentionally introduce an element of confusion. It could be a reading similar to the one used here, a recording of real students sharing their experiences, or an exercise that forces awareness of unknown processes. Librarians are encouraged to try various ways to generate awareness of what needs to be learned and to share their experiences with colleagues. This will enable librarians to develop reliably effective brief interventions that serve to improve students' information literacy.

\section{References}

1. Samuel S. Green, "Personal Relations between Librarians and Readers," Library Journal 1, no. 2-3 (November 1876): 74-81.

2. Charles A. Bunge, "Interpersonal Dimensions of the Reference Interview: A Historical Review of the Literature," Drexel Library Quarterly 20, no. 2 (Spring 1984): 4-23.
3. Ibid.

4. Peter Brophy, "Narrative Based Practice," Evidence Based Library and Information Practice 2, no. 1 (2007): 149-58.

5. Loriene Roy, "Once upon a Time: Storytelling and Its Place in the Teaching of Reference," Reference Librarian 57, no. 3 (2016): 242-46.

6. Ralph Gers and Lillie J. Seward, "Improving Reference Performance: Results of a Statewide Study," Library Journal 110, no. 18 (November 1, 1985): 32-35.

7. Peter Hernon and Charles McClure, "Unobtrusive Reference Testing: The 55 Percent Rule," Library Journal 111, no. 7 (April 15, 1986): 37-41.

8. Joan C. Durrance, "Reference Success: Does the 55 Percent Rule Tell the Whole Story?," Library Journal 114, no. 7 (April 15, 1989): 31-36.

9. RASD Ad Hoc Committee on Behavioral Guidelines for Reference and Information Services, "RUSA Guidelines for Behavioral Performance of Reference and Information Service Professionals," RQ 36, no. 2 (Winter 1996): 200-203.

10. Catherine Sheldrick Ross and Patricia Dewdney, "Negative Closure: Strategies and Counter-Strategies in the Reference Transaction," Reference \& User Services Quarterly 38, no. 2, (1998): 15163.

11. Jody Fagan, "Students' Perceptions of Academic Librarians," Reference Librarian 37, no. 78 (2003): 131-48.

12. Constance A. Mellon, "Library Anxiety: A Grounded Theory and Its Development," College \& Research Libraries 47, no. 2 (March 1986): 160-65.

13. Jane Keefer, "The Hungry Rats Syndrome: Library Anxiety, Information Literacy, and the Academic Reference Process," RQ 32, no. 3 (Spring 1993): 333-40.

14. Catherine M. Robinson and Peter Reid, "Do Academic Enquiry Services Scare Students?," Reference Services Review 35, no. 3 (August 2007): 405-24.

15. Shelly Blundell and Frank Lambert, "Information Anxiety from the Undergraduate Student Perspective: A Pilot Study of SecondSemester Freshmen," Journal of Education for Library and Information Science 55, no. 4 (Fall 2014): 261-73.

16. Alison J. Head, Learning the Ropes: How Freshmen Conduct Course Research Once They Enter College, Project Information Literacy, December 4, 2013, http://www.projectinfolit.org /uploads/2/7/5/4/27541717/pil_2013_freshmenstudy_report _no_appendicesv2.pdf.

17. Nahyun Kwon, "A Mixed-Methods Investigation of the Relationship between Critical Thinking and Library Anxiety among Undergraduate Students in their Information Search Process," College \& Research Libraries 69, no. 2 (March 2008): 117-31.

18. William Collins and Brian C. Sims, "Help Seeking in Higher Education Academic Support Services," in Help Seeking in Academic Settings: Goals, Groups, and Contexts, ed. Stuart A. Karabenick and Richard S. Newman (Mahwah, NJ: Lawrence Erlbaum Associates, 2006), 203-23.

19. Justin Kruger and David Dunning, "Unskilled and Unaware of It: How Difficulties in Recognizing One's Own Incompetence Lead to Inflated Self-Assessments," Journal of Personality and Social Psychology 77, no. 6 (December 1999): 1121-34.

20. Claude M. Steele, "A Threat in the Air: How Stereotypes Shape Intellectual Identity and Performance," American Psychologist 52, no. 6 (June 1997): 613-29.

21. Allison M. Ryan and Paul R. Pintrich, "Achievement and Social Motivational Influences on Help Seeking in the Classroom," in Strategic Help Seeking: Implications for Learning and Teaching, ed. Stuart A. Karabenick (Mahwah, NJ: Lawrence Erlbaum Associates, 1998), 117-39.

22. Mellon, "Library Anxiety."

23. David S. Yeager and Gregory M. Walton, "Social-Psychological Interventions in Education: They're Not Magic," Review of 
Educational Research 81, no. 2 (June 2011): 267-301.

24. Ibid.

25. Gregory M. Walton et al., "Mere Belonging: The Power of Social Connections," Journal of Personality and Social Psychology 102, no. 3 (Mar. 2012): 513-32.

26. Gregory M. Walton and Geoffrey L. Cohen, "A Brief SocialBelonging Intervention Improves Academic and Health Outcomes of Minority Students," Science 331, no. 6023 (March 18, 2011): 1447-51.

27. Gregory M. Walton and Geoffrey L. Cohen, "A Question of Belonging: Race, Social Fit, and Achievement," Journal of Personality and Social Psychology 92, no. 1 (January 2007): 82-96.

28. Brian Spitzer and Joshua Aronson, "Minding and Mending the Gap: Social Psychological Interventions to Reduce Educational Disparities," British Journal of Educational Psychology 85, no. 1 (March 2015): 1-18.

29. Timothy D. Wilson, Michelle Damiani, and Nicole Shelton, "Improving the Academic Performance of College Students with Brief Attributional Interventions," in Improving Academic
Achievement, ed. Joshua Aronson (New York: Academic Press, 2002), 89-108.

30. Rory A. Lazowski and Chris S. Hulleman, "Motivational Interventions in Education: A Meta-Analytic Review," Review of Educational Research 86, no. 2 (June 2016): 602-40.

31. Ibid., 628.

32. Mellon, "Library Anxiety."

33. Carol C. Kuhlthau, "Inside the Search Process: Information Seeking from the User's Perspective," Journal of the American Society for Information Science 42, no. 5 (June 1991): 361-71.

34. Head, Learning the Ropes.

35. "QUAID Tool," accessed June 16, 2015, http://quaid.cohmetrix .com/.

36. Wilson, Damiani, and Shelton, "Improving the Academic Performance of College Students with Brief Attributional Interventions."

37. Barry M. Kroll, Teaching Hearts and Minds: College Students Reflect on the Vietnam War in Literature (Carbondale: Southern Illinois University Press, 1992).

\section{APPENDIX}

\section{Facts about the library administered to randomly selected control group}

[Edited lightly to remove identifying information]

Instructions: First read this passage, then turn the page over and indicate your level of agreement to the statements.

The Library has approximately 220,000 books, 300 subscriptions to print journals, and 1500 DVDs. The library's web page links to 60 online databases and the library catalog. These give students access to 100,000 e-books and 73,000 online journals, magazines, and newspapers.

The [discovery service] on the library home page allows students to search everything at once. Students can also search for information in one topic area. Each topic area has a "Research by Subject" guide. The guides are custom made by the librarians. Guides include a custom version of [discovery service], links to the most relevant databases, and selected trustworthy web resources. Some guides also include video tutorials. These have tips for how to search databases like PsycINFO and ERIC.

The library offers students help in several ways. The librarians provide reference service 92 hours per week. Students may ask questions at the reference desk any time the library is open. Students may schedule one-on-one assistance with our librarians. Librarians can be contacted via a web form, email, phone or text. Librarians also visit classes to describe the best ways to use the library.

The library has many seating options for work and study: soft chairs to curl up in, tables to spread out on, study carrels, and group and individual study rooms. The library has 30 PCs and 20 Macs. Students may check out one of 20 laptops from the circulation desk.

If a student finds a book or article that is not part of the library's print or online collections, the library has an interlibrary loan service. The library will obtain the item for you from another library. The library also has a scanning service.
Students can request a PDF scan of an article from our print journal collection.

\section{Narrative describing students' positive interactions with librarians while conducting research administered to randomly selected treatment group}

Instructions: First read this passage, then turn the page over and indicate your level of agreement to the statements.

Seniors describe their experiences of learning to do research in the college library-

"I was a little scared at first," said Alyssa. "In high school I just used textbooks and what I could find searching Google, so when my professors told me to use library databases and peer-reviewed literature I wasn't totally sure what they were asking me to find."

"Yeah, that was me, too," added Chris, "and I felt stupid asking. But when I asked a librarian for help, she was really nice about it. The librarians were easy to talk with, even when I needed something explained more than once. And the information I found was better than the stuff I was getting with Google."

"Me, I thought how hard can this be? I'll figure it out myself," said Eric. "But then I was using this one database and just kept going around in circles. I got really frustrated, and went to the reference desk to complain about how hard it was to use. The librarian listened and asked me what I was trying to do, then he showed me some tricks that worked to get what I wanted. If I'd asked in the first place I would've saved myself a lot of time."

"Time was big for me, too," said Alyssa. "I mostly learned by putting in the hours to get good at searching databases and doing all the hard work to write a good research paper. But the couple of times I asked for help from librarians, it saved me work. They're like coaches. You can learn on your 


\section{FEATURE}

own, but the tips they give for how to do stuff are really useful."

"I agree," said Chris. "Still, I was surprised by how much time I had to put in to get really good at research. It takes practice, but now I feel like an expert. Still, I've learned to ask right away if I hit trouble, like if I'm writing a paper for an elective class outside my major." 